\title{
O DESENVOLVIMENTO PROFISSIONAL DOCENTE E O DIÁLOGO ENTRE CIÊNCIA E RELIGIÃO
}

Ana Paula Albonette de Nóbrega - prof.ananobrega@gmail.com ${ }^{1}$ Elane Chaveiro Soares - elaneufmt@gmail.com²

Resumo - O presente texto se refere a uma pesquisa desenvolvida no âmbito de um mestrado profissional em ensino de ciências naturais e visou possibilitar um diálogo entre ciência e religião nas aulas de ciências naturais no ensino médio a partir da elaboração de um livro paradidático. A fundamentação teórica entrelaçou três campos de conhecimentos: formação de professores, concepções de ciência e relacionamento entre ciência e religião. Para conhecer qual a contribuição do diálogo entre tais campos no ensino de ciências naturais, realizamos uma pesquisa qualitativa do tipo estudo de caso. A análise dos instrumentos de pesquisa foi feita a partir da técnica da análise textual discursiva. Os resultados obtidos demonstram que o professor que se percebe em desenvolvimento profissional consegue proporcionar um diálogo ético, tolerante e construtivo entre ciência e religião no exercício de sua prática pedagógica.

Palavras-chave: Desenvolvimento profissional docente, Diálogo entre ciência e religião, Ensino de ciências naturais.

\section{TEACHER PROFESSIONAL DEVELOPMENT AND THE DIALOGUE BETWEEN SCIENCE AND RELIGION}

\begin{abstract}
The present text refers to a research developed within the scope of a master's professional mode post-graduate program, in the teaching of Natural Sciences whose aimed to enable a dialogue between religion and science in natural science student classes in high school, by the elaboration of a paradidactic book. The theoretical foundation comprised three fields of knowledge: Teacher education, Science concepts and the relationship between religion and science. Therefore, to understand what the dialogue between these fields contributed in the teaching of natural sciences, we did a qualitative case study research. The analysis of the research instruments was made by the technique of discursive textual analysis. The results obtained demonstrate that the teacher is able to provide an ethical dialogue, tolerant and constructive between science and religion in the exercise of their teaching practice when he realizes he is developing professionally.

Keywords: Professional teacher development, Dialogue between religion and science, Teaching of natural science.
\end{abstract}

Data de Submissão: 30/01/2020

Data de Aceitação: 01/08/2020 


\section{Introdução}

A pesquisa aqui relatada foi desenvolvida no âmbito de um mestrado profissional em ensino de ciências naturais (PPGECN/UFMT) e buscou investigas e ao mesmo tempo propor a possibilidade de um diálogo entre ciência e religião nas aulas de ciências naturais no ensino médio'.

Concordamos inicialmente que o professor precisa estar em constante desenvolvimento profissional docente para que possa realizar um ensino de ciências significativo. Esse desenvolvimento envolve, portanto, todas as experiências de aprendizagem planejadas, ou seja, a formação inicial e os cursos de formação continuada, e ainda, as experiências profissionais e pessoais.

Dessa forma, a vivência do professor nas mais variadas dimensões de sua vida cotidiana, acadêmica e profissional - cultural e social - é propulsora de movimentos epistemológicos que modificam sua forma de relacionar-se com o conhecimento e com o mundo. Durante a prática pedagógica, o professor é interpelado por diversas dúvidas, incluindo aquelas de cunho religioso. Concentramos nossa expectativa e nossa metodologia de pesquisa nesse ponto, onde procuramos abordar a contribuição do diálogo entre ciência e religião para o ensino de ciências naturais.

Dada a repercussão e até mesmo, certa polêmica em torno da temática proposta, nossa hipótese emergiu de uma postura singela, mas, não menos ousada, onde o argumento girou em torno da afirmativa de que a ciência pode ser ensinada nas escolas de uma forma diferente, mais engajada e menos dogmática. Objetivamos sem ressalvas, promover a ampliação de conhecimentos sobre a natureza, o escopo e as limitações da ciência, discorrendo de forma didática, atrativa e lúdica sobre as possíveis interações entre ciência e religião no âmbito do ensino de ciências naturais.

A fundamentação teórica entrelaçou três campos de conhecimento: Formação de professores (com ênfase no desenvolvimento profissional docente) baseada em André (2010), Day (2001), Marcelo Garcia (1999), Marcelo (2009) e Tardif (2010); Concepção de ciência a partir de Chalmers (1993), Chassot (2004), Granger (1994), Ronan (2001) e Gil-Perez et al. (2001); e, finalmente em uma proposta de relacionamento entre os campos da ciência e da religião baseados em Alexander (2007), Barbour (2004), Japiassu (2005) e McGrath (2005), com destaque para Barbour (2004), que nos trouxe a compreensão dos modelos utilizados para descrever a relação entre ciência e religião.

Como a pesquisa foi desenvolvida a partir de um mestrado profissional, construímos, como produto educacional, um livro paradidático intitulado: "Ciência e Religião no Ensino de Ciências Naturais: Pode isso?" ${ }^{2}$ dando destaque a um questionamento normalmente presente em alguns âmbitos acadêmicos, onde se pressupõe - a partir do modelo do conflito - que ciência e religião são campos incompatíveis ou simplesmente independente. E que, qualquer proposta

1 Como o tema, desde o início, despertou curiosidade e até, certo incômodo no ambiente acadêmico, julgamos necessário e importante destacar que temos, enquanto professoras e pesquisadoras no âmbito do ensino de ciências, alguns pressupostos básicos: 1. Em nenhum momento se intentou promover o ensino religioso no lugar do ensino das ciências; 2. Não se objetivou tirar ou diminuir a relevância do ensino de ciências feito nas escolas, pelo contrário e 3. A ciência, sua história e natureza, no decurso do desenvolvimento da humanidade, não pode ser deslocada de outros campos do saber, nem mesmo do religioso. Tais pressupostos permearam a escolha da fundamentação teórica, da metodológica bem como, da construção de conhecimento da pesquisa aqui relatada. 2 Disponível no sítio do PPGECN/UFMT: http://fisica.ufmt.br/pgecn/ 
que promova algum tipo de aproximação é inicialmente considerada anticiência.

Na metodologia, organizamos uma oficina intitulada: "Ciência e religião dialogando?" onde participaram 13 (treze) professores do ensino médio de uma escola pública da cidade de Cuiabá-MT. Nessa oficina, aplicada em outubro de 2019, os sujeitos leram na íntegra o livro paradidático e responderam aos instrumentos de pesquisa - posteriormente, alguns foram entrevistados. Para a exploração das respostas utilizamos a técnica da análise textual discursiva (MORAES; GALIAZZI, 2011).

Os resultados obtidos indicam que o professor que se percebe em desenvolvimento profissional, consegue, a partir da compreensão de sua cosmovisão, proporcionar um diálogo ético, tolerante e construtivo entre ciência e religião no exercício de sua prática pedagógica. Apontaram ainda para a necessidade de superação de muitos equívocos construídos ao longo da formação inicial, dentre os quais, a ênfase na impossibilidade da existência de um diálogo entre os campos mencionados.

\section{Um Percurso Planejado}

A escolha do tema, ciência e religião, dentro da perspectiva do DPD surgiu, a partir de alguns questionamentos que me fizeram repensar a prática docente no âmbito do cotidiano do ensino (Autor 1). Dois deles eu trago aqui: Os conteúdos e a própria história da ciência só podem ser contados/ensinados através da visão positivista? Existe outra forma de abordar o conhecimento científico que não da maneira naturalista ou proposta pelos livros didáticos convencionais?

O ingresso no mestrado foi a alavanca necessária para construir a pesquisa aqui relatada e que está conectada ao projeto já existente denominado de Desenvolvimento Profissional Docente em Ciências e Matemática e as crenças religiosas: transformar, superar ou considerar? Nesta conexão, trabalhamos para aprofundar teoricamente a proposta maior e também para construir um produto educacional no formato de um livro paradidático que pudesse chegar às mãos de professores e de alunos e que promovesse o diálogo entre os campos da ciência e da religião.

Para além da vivência profissional, a relevância do tema apareceu, a partir de um levantamento bibliográfico, utilizado como suporte para a construção de uma pesquisa do tipo estado da questão, que permitiu ressignificar nossos saberes iniciais a respeito do tema. Tal levantamento foi feito no banco de teses e dissertações da Capes, e, a partir dele, percebemos que o diálogo entre ciência e religião é sim, uma questão emergente, importante e produtiva de saberes que vem acontecendo em vários níveis acadêmicos, como de mestrado e doutorado, em universidades confessionais e de cunho laico. Perceber isso nos investiu de mais propriedade e anseio por desenvolver a temática dentro do mestrado em ensino de ciências naturais oferecido pela UFMT.

O objeto da pesquisa aqui relatada foi o diálogo entre ciência e religião dentro das aulas de ciências naturais no ensino médio. Esse objeto se materializou como um livro paradidático intitulado "Ciência e Religião no Ensino de Ciências Naturais: Pode isso?" criado a fim de subsidiar uma formação mais apurada com vistas a um DPD que contemple essa discussão. $\mathrm{O}$ objetivo foi promover a ampliação de conhecimentos sobre a natureza, o escopo e as limitações 
da ciência, discorrendo de forma didática, atrativa e lúdica sobre as possíveis interações entre ciência e religião no âmbito do ensino de ciências naturais.

A escolha pela produção de um livro paradidático se baseou, portanto, na vontade de contribuir para a existência de um diálogo rigoroso, respeitoso e tolerante entre ciência e religião, passando sumariamente pela necessidade de transformar a formação inicial de professores de ciências que outrora fora controlada pelo materialismo histórico e pelo suposto cunho neutro da ciência, dentre outras visões deformadas (GIL-PEREZ et al., 2001) e que estão, de certa forma, impregnados na prática docente.

\section{Metodologia}

A metodologia escolhida ${ }^{3}$ para sustentar a execução deste trabalho foi a pesquisa qualitativa do tipo estudo de caso, uma vez que esse tipo de pesquisa "preocupa-se com a compreensão, com a interpretação do fenômeno, considerando o significado que os outros dão às suas práticas, o que impõe ao pesquisador uma abordagem hermenêutica. " (GONSALVES, 2007, p. 69).

Para conhecer os significados atribuídos a essa proposta de diálogo pelos sujeitos da pesquisa, observamos as recomendações de Bogdan e Biklen (1994). Os autores inferem que os estudos de caso necessitam de um local específico dentro de uma organização, de um grupo específico de pessoas e de uma atividade escolar. Sendo assim, escolhemos a Escola Estadual Liceu Cuiabano "Maria de Arruda Müller" (doravante referenciada apenas como Liceu Cuiabano) localizada no município de Cuiabá-MT como local, os professores das áreas de ciências naturais e matemática como grupo de pessoas e um encontro de formação continuada, que ocorreu dentro da própria unidade escolar, como atividade.

Para a coleta de dados, foram construídos três instrumentos: 1. Questionário de partida (conhecer como os sujeitos da pesquisa concebem o diálogo entre ciência e religião); 2. Questionário final (para validação do produto educacional) e 3. Entrevista semiestruturada (aprofundar a investigação e compreender as contribuições que o livro paradidático produzido pode trazer para o ensino de ciências naturais e de matemática).

Os 13 (treze) sujeitos participantes da pesquisa receberam um arquivo digital com o livro paradidático e responderam aos instrumentos em uma plataforma on line. A posteriori, foram escolhidos 4 (quatro) sujeitos para participar da entrevista semiestruturada, sendo um de cada disciplina (biologia, física, química e matemática). Para a seleção entre os professores da mesma disciplina, nos pautamos no modelo mental de relacionamento entre ciência e religião (BARBOUR, 2004) indicado pelos professores em uma questão no questionário de partida.

Para o procedimento de exploração das respostas dadas pelos sujeitos da pesquisa aos instrumentos de coletas de dados, utilizamos a análise textual discursiva (MORAES; GALIAZZI, 2011) daqui em diante representada pela sigla ATD.

De acordo com Moraes e Galiazzi (2011), a ATP se inicia com a definição do corpus da pesquisa, ou seja, o conjunto de textos que serão analisados. Em seguida, o processo deverá

3 O projeto de pesquisa foi encaminhado ao Comitê de Ética em Pesquisa com Seres Humanos da Área das Ciências Humanas e Sociais da Universidade Federal de Mato Grosso e, no dia 10 de agosto de 2019, recebeu aprovação. 
ser organizado de acordo com quatro focos: 1. Refere à desmontagem dos textos, ou unitarização. Nessa primeira etapa, examinamos minuciosamente as respostas dadas pelos sujeitos, fragmentando-as, buscando um sentido para as respostas; 2. Busca por relações entre as unidades produzidas na etapa anterior, também chamado de categorização. As categorias podem ser construídas a partir do método dedutível, ou seja, quando o pesquisador constrói as categorias antes mesmo de iniciar a pesquisa, são as categorias a priori; 3. Captação do novo emergente. Devido à intensa dedicação nos dois focos anteriores, surge uma nova compreensão acerca do assunto analisado. Assim, se constrói o metatexto, ou seja, o produto construído a partir da combinação dos elementos provenientes dos passos anteriores e; 4. Auto-organização, ou seja, o ciclo de análise que possibilita a evidência de novas compreensões acerca do que se está estudando.

Usando a mesma metáfora de Moraes e Galiazzi (2011), a ATD se inicia como uma explosão de ideias, na qual se realiza uma desconstrução que possibilitará a análise e uma futura reconstrução, num processo de síntese. "Estas reconstruções são necessariamente afetadas pelas concepções teóricas do pesquisador, por suas teorias e sua visão de mundo. " (MORAES; GALIAZZI, 2011, p. 53).

Assim, as compreensões que surgem a partir da ATP podem ser comparadas a alimentar um caldeirão de ideias. Esse caldeirão é alimentado pelas ideias produzidas a partir do próprio pesquisador, das ideias obtidas a partir de diálogos com outros sujeitos e com as ideias produzidas a partir de interlocutores teóricos. O produto final dessa mistura inteligente de informações corresponde às novas compreensões oriundas da ATD.

\section{Aspectos a considerar no Desenvolvimento Profissional Docente}

A profissão docente requer capacidades diferentes de outras profissões. Segundo Tardif (2010, p. 39)

\footnotetext{
O professor ideal é alguém que deve conhecer sua matéria, sua disciplina e seu programa, além de possuir certos conhecimentos relativos às ciências da educação e à pedagogia e desenvolver um saber prático baseado em sua experiência cotidiana com os alunos.
}

Dessa forma, um professor não pode ser considerado como um produto acabado ao término de sua formação inicial, mas sim, deve compreender a importância de estar em constante formação e evolução, tal fato traz a concepção de desenvolvimento profissional, indicando a premência de um contínuo de aprendizagem (MARCELO GARCIA, 1999).

Marcelo $(2009$, p. 9) define que "o conceito desenvolvimento tem uma conotação de evolução e continuidade que, em nosso entender, supera a tradicional justaposição entre formação inicial e formação contínua dos professores. "Assim, concebemos que, para atender as necessidades educacionais, o professor deve se identificar como um profissional do ensino e sempre buscar desenvolver-se.

O desenvolvimento profissional envolve todas as experiências espontâneas de aprendizagem e as atividades conscientemente planificadas, realizadas para benefício direto ou indireto do indivíduo, do grupo ou da escola e que contribuem, através destes, para a qualidade da educação na sala de aula. É o processo através do qual os professores, enquanto agentes de 
mudança, reveem, renovam e ampliam, individual ou coletivamente, o seu compromisso com os propósitos morais do ensino, adquirem e desenvolvem, de forma crítica, juntamente com as crianças, jovens e colegas, o conhecimento, as destrezas e a inteligência emocional, essenciais para uma reflexão, planificação e práticas profissionais eficazes, em cada uma das fases das suas vidas profissionais.

Podemos considerar que o DPD se baseia em quatro tipos de saberes: os saberes oriundos da formação inicial, os saberes construídos durante processos de formação continuada, os saberes provenientes das experiências profissionais do professor e os saberes que compõem as experiências pessoais.

Marcelo Garcia (1999) evidencia quatro tipos de conhecimentos que devem ser adquiridos ao longo da formação inicial de professores: 1. Conhecimento psicopedagógico: aqueles relacionados com o ensino e a aprendizagem dos alunos; 2. Conhecimento de conteúdo: se refere aos conteúdos que serão ensinados pelo professor; 3. Conhecimento didático de conteúdo: que se indicam a combinação adequada entre o conhecimento de conteúdo e o conhecimento pedagógico e didático; 4. Conhecimento do contexto: conhecimento do local onde se ensina e do público para quem se ensina.

Outro autor que contribui com a discussão é Day (2001, p. 203), onde destaca que a formação continuada é "um acontecimento planejado, um conjunto de eventos ou um programa amplo de aprendizagens acreditadas ou não acreditadas". O referido autor considera relevante a busca de formação a partir de cursos provenientes de instituições (aprendizagens acreditadas) e da própria escola (não acreditadas). São ações pontuais e com objetivos definidos.

Marcelo Garcia (1999, p. 28) acrescenta ainda que, "os professores, enquanto profissionais do ensino, desenvolvem um conhecimento próprio, produto das suas experiências e vivências pessoais, que racionalizaram e inclusive rotinizaram. " Assim, ao pensar sobre sua prática docente, os professores constroem saberes experienciais, referentes a seu fazer pedagógico. Esse conhecimento próprio demonstra, dentre outras coisas, que os professores são profissionais reflexivos, ou seja, são capazes de conhecer e aprender com sua prática.

Concernentes aos saberes docentes, aprendemos com as pesquisas que todas as experiências que o professor viveu enquanto aluno em toda a sua jornada escolar, influenciarão sua prática docente. Afinal, "uma boa parte do que os professores sabem sobre o ensino, sobre os papéis do professor e sobre como ensinar provém de sua própria história de vida, principalmente de sua socialização enquanto alunos." (TARDIF, 2010, p. 68). E ainda que, "não existe uma maneira objetiva ou geral de ensinar; todo professor transpõe para a sua prática aquilo que é como pessoa." (TARDIF, 2010, p. 144-145). Afinal, o professor tem sentimentos, emoções e história que são levadas para a sala de aula. Assim, as experiências pessoais e a visão pessoal de mundo também compõem o profissional do ensino.

Notamos que os professores devem perceber a importância de serem protagonistas de seu desenvolvimento profissional. Há a necessidade de o professor se perceber como parte dos processos que ocorrem em sala de aula. De pensar, analisar, chegar a conclusões, refletindo, cotidianamente, com salutar intencionalidade, a sua própria prática docente.

Aqueles professores que investigam a sua prática, saem do conhecimento implícito, 
aquele baseado nas suposições criadas durante a prática pedagógica, e alcançam a solução para os mais diversos problemas do cotidiano profissional docente. Como destaca Day (2001, p. 47):

\begin{abstract}
Os professores que refletem na, sobre e acerca da ação empenham-se numa investigação com vista não só a uma melhor compreensão de si próprios enquanto professores, mas também tendo em vista a melhoria do seu ensino.
\end{abstract}

Ocorre que, no exercício da profissão, os professores se deparam com situações que carecem de outros conhecimentos, como os culturais, por exemplo. Para atender à necessidade de equalização dos saberes docentes, devem desenvolver certa aptidão para trabalhar com a educação intercultural. Isso quer dizer que o profissional deve "integrar o conceito de diversidade cultural nos próprios conteúdos e metodologias de ensino, entendendo que a diversidade diz respeito à raça, mas também ao sexo, religião, classe social, capacidade, etc." (MARCELO GARCIA, 1999, p. 92).

Nesse sentido, os professores devem buscar diversificadas oportunidades de desenvolvimento profissional, incluindo aquelas que "ultrapassem largamente o instrumentalismo que impregna grande parte das práticas atuais, de forma que sejam estimulados a ir ao encontro das necessidades de aprendizagem dos alunos. "(DAY, 2001, p. 42).

Ao longo de sua vida profissional, o professor se envolverá em inúmeros processos formativos. André (2010) afirma que tais processos formativos intencionais e planejados devem possibilitar mudanças em direção à uma melhoria da prática efetiva em sala de aula. Marcelo (2009, p. 15) colabora com essa ideia ao dizer que "o desenvolvimento profissional procura promover a mudança junto dos professores, para que estes possam crescer enquanto profissionais - e também como pessoas".

Tais afirmações nos trazem uma angustia: a quais mudanças esses autores estão se referindo? Marcelo (2009) afirma que muitas pesquisas estão sendo feitas sobre os processos de mudanças nos docentes e que existe mais destaque no que se refere aos preconceitos e crenças dos docentes. Ele entende crenças "como as proposições, premissas que as pessoas têm sobre aquilo que consideram verdadeiro." (MARCELO, 2009, p. 15).

No cotidiano de nossa prática docente, somos bombardeados por inúmeros questionamentos dos alunos. Além das perguntas que são respondidas a partir das experiências formais de aprendizagem e das experiências escolares - aquelas relacionadas intrinsecamente ao conteúdo - existem perguntas que transcendem a formalidade de um sumário de livro ou de um plano de aula. São perguntas curiosas que vasculham nossa identidade profissional, mas que, muitas vezes avançam para o campo dos valores e das crenças. É comum fugir deste diálogo, afinal, fomos capacitados para ensinar esta ou aquela ciência e não preparados para os embates históricos e epistemológicos dos saberes que são ensinados na escola. Aliás, comumente aprendemos que o saber científico é neutro, não contraditório, pleno e, íntegro, ou seja, não passível de questionamento (GIL-PEREZ et al., 2001).

Dessa forma, entendemos como contraditória a ideia de que as crenças e os valores dos professores podem ser desconsiderados no desenvolvimento profissional. E mais abusiva ainda, a ideia de que, crenças e valores podem ou precisam ser transformados nesse processo. Tal afirmativa está baseada na perspectiva constitutiva de um profissional docente que possui uma personalidade - que tem liberdade de crer e de valorar certas crenças - e que se colocará na 
posição de alguém que responsavelmente irá desenvolver uma identidade profissional docente sem necessariamente desfigurar sua história.

Tal posicionamento nos impulsiona para a ideia do diálogo entre ciência e religião que se configura no presente século como um tabu a ser quebrado. Pois, como professores de ciências somos inquiridos a todo tempo, sobre o conceito de verdade e não há como fugir das questões sobre o saber científico e o saber religioso.

Algumas perguntas podem causar espanto e até mesmo constrangimento aos professores, especialmente aquelas de cunho religioso. Ademais, há o presente pressuposto que ciência e religião estão em conflito ou, que não é viável, ou mesmo relevante para um professor de ciências tratar/lidar/compreender/mencionar dados advindos do campo da religião.

O DPD pode colaborar com a formação de um professor que possa responder a questionamentos como esses de forma a não construir visões deformadas da ciência (GIL-PEREZ et al., 2001) nem de ser simplório no que se refere à religião, mas sim de poder ajudar os alunos a interpretarem e utilizarem a ciência - ou o saber científico - sem que necessariamente tenha que deixar de viver sua religião. Com todo o cuidado e principalmente com tolerância de ideias, o DPD assegurará uma maior qualidade na prática docente.

\title{
Construindo uma compreensão do que é Ciência
}

Não é simples definir ciência. Ao realizar uma pesquisa superficial de sua definição nas plataformas de buscas da internet, a maioria dos resultados encontrados se refere à ciência como o conhecimento dos fenômenos da natureza explicados a partir do método experimental, o método científico.

Outra definição para ciência foi proposta por Japiassu e Marcondes (2006, p. 44):

\begin{abstract}
Ciência é um saber metódico e rigoroso, é um conjunto de aquisições intelectuais que tem por finalidade propor uma explicação racional e objetiva da realidade. É a forma de conhecimento que não somente pretende apropriar-se do real para explicá-lo de modo racional e objetivo, mas procura estabelecer entre os fenômenos observados relações universais e necessárias, o que autoriza a previsão de resultados cujas causas podem ser detectadas mediante procedimentos de controle experimental.
\end{abstract}

Observando essas definições, compreendemos que ciência é um campo de conhecimentos que busca explicar os fenômenos da natureza. Tais explicações são construídas a partir de pesquisa, experimentação, formulação de teorias, entre outras etapas do método científico. $\mathrm{Ou}$ seja, é um campo de conhecimentos que possui uma metodologia própria.

Ao considerarmos que a verdade sobre a ciência se encontra somente nas afirmações anteriores, podemos formar o que Gil-Perez et al. (2001) chamam de visões deformadas do trabalho científico. Em seu trabalho, os autores apresentam sete características do trabalho científico que colaboram para um entendimento distorcido. São elas:

1- Concepção empírico-indutivista e ateórica;

2- Visão rígida; 
3- Visão aproblemática e ahistórica (dogmática e fechada);

4- Visão exclusivamente analítica;

5- Visão acumulativa de crescimento linear;

6- Visão individualista e elitista da ciência;

7- Imagem socialmente neutra da ciência.

Observando as características de uma visão deformada do trabalho científico, podemos perceber a premência da busca por compreensões mais profundas acerca do que realmente seja ciência. Um bom ponto de partida é conhecer a história desse campo de conhecimentos.

A ciência, tal como conhecemos hoje, começou a adquirir status com a Revolução Científica, no século XVI. Copérnico, Kepler, Galileu, Bacon, Descartes e Newton são os principais personagens dos processos de mudanças no campo de conhecimento designado então por filosofia natural. Tais processos suscitaram a origem do que se chama ciência moderna.

Não existe um marco histórico do surgimento da ciência, haja vista que os seres humanos utilizam os conhecimentos da ciência desde sempre. Podemos apresentar inúmeras atividades realizadas pelo ser humano primitivo que ilustram a afirmação anterior. Chassot (2004) traz uma gama de atividades realizadas por esses povos: produção e conservação do fogo, cocção dos alimentos, transformação do ser humano nômade em pastores de rebanhos e agricultores, noção de anatomia animal e vegetal, metalurgia, aritmética, entre muitos outros. Portanto, mesmo sem sistematização, os conceitos estudados pela ciência já estavam presentes na vida humana desde o princípio.

O início da sistematização da ciência se deu na Grécia Antiga. A primeira vez que um fenômeno da natureza foi explicado sem a evocação de poderes sobrenaturais foi com Tales de Mileto, ele propôs que "a água era o constituinte básico de todas as coisas" (RONAN, 2001a, p. 70). Além disso, ele criou um método de cálculos de distância utilizando a semelhança de triângulos.

Quando estudamos a Grécia Antiga é importante ressaltar a presença de vários deuses. Chassot (2004, p. 38) nos diz que "a função principal da religião grega consistia em interpretar a natureza e seus processos em termos inteligíveis, isto é, fazer com que o homem se sentisse no mundo como em sua casa. " Os gregos buscavam a razão para explicar o mundo, surgiu assim, a filosofia grega.

No começo da era cristã, com a Grécia sob o poderio do Império Romano, o pensamento filosófico se conciliou com a nova religião. Tal fato fez com que a tradição filosófica diminuísse e ficasse reclusa à Igreja. A ciência grega era vista pelos Pais da Igreja como paganismo, pois ela tentava romper com explicações mitológicas ou religiosas, trazendo outras visões para os fenômenos naturais, dessa forma, foi desencorajada, dificultada ou ignorada por eles (HARISSON, 2017)

Continuando o caminho pela história da ciência, chegamos na Idade Média, compreendida entre o fim da Idade Antiga, século V, até o surgimento do Renascimento, século XIV. Existem muitas especulações sobre o que aconteceu com a ciência em tal período histórico. 
Na Idade Média, a religião sofre transformações. Antes, cada povo, usando uma abordagem generalista, apresentava seu sistema de crenças. Com o advento do cristianismo, formou-se uma concepção de religião universal. Dois fatos foram os principais motivadores para a ascensão do cristianismo na Europa: 1- Ele foi adotado como religião oficial do Império Romano, no século IV d. C. pelo imperador Constantino; e 2- A concepção de história e a teoria da natureza humana e da iluminação divina de Santo Agostinho (MARCONDES, 2001).

Sendo assim, a Igreja detinha um grande poder, não apenas espiritual, mas também nas áreas políticas e econômicas (CHASSOT, 2004). A Igreja era "a única instituição estável e a principal e quase exclusiva responsável pela educação e pela cultura. " (MARCONDES, 2001, p. 115) ela veiculava os conhecimentos anteriores, principalmente os textos que eram compatíveis ao cristianismo.

Durante a Idade Média, podemos observar uma série de divergências entre os cristãos. Por um lado, estudar o mundo criado por Deus provocaria uma sensação de esplendor e uma admiração pelas maravilhas de Sua obra. Por outro lado, significava voltar às fontes gregas, ou seja, aos ensinamentos pagãos, o que poderia contaminar a mente do fiel. Portanto, a Igreja deu pouca importância à ciência, seu uso ficou restrito às necessidades específicas, como por exemplo, o uso do calendário lunar para a definição da Páscoa, técnicas de agricultura e controle de epidemias (RONAN, 2001b).

O final do primeiro milênio contemplou uma guinada na tradição da filosofia cristã: o influxo do ensino grego. Algumas obras, principalmente de Aristóteles foram traduzidas para o latim, o que possibilitou o conhecimento de tais textos.

Assim, a partir do século XI, cada abadia ou catedral tinha uma escola "onde se ensinavam os elementos básicos da cultura da época, o trivium, ou três vias, consistindo de uma introdução à gramática, lógica e retórica, e o quadrivium, ou quatro vias, composto de música, geometria, aritmética e física." (MARCONDES, 2001, p. 116).

Além disso, surgem as Universidades que disseminavam o conhecimento para aqueles poucos que podiam pagar pelo estudo. A primeira foi a Universidade de Bolonha, no século XI, com a escola de direito e a segunda foi a Universidade de Paris, no século XII (CHASSOT, 2004). As universidades colaboraram com a propagação de conhecimentos que estimularam as mudanças necessárias para o surgimento do período conhecido por Renascimento.

As traduções e disseminações de textos antigos, as descobertas de novas terras a partir das grandes navegações, o surgimento do papel e da imprensa, o comércio de livros impressos pela China, entre outras importantes invenções, trouxeram novos ideais e expectativas para a sociedade. Esse período de mudanças, do século XIV ao século XVI, ficou conhecido como Renascença (RONAN, 2001c).

A religião foi muito influenciada durante o período da Renascença. A tradução da Bíblia, a possibilidade de impressão de muitas cópias e a necessária reorganização das ações da Igreja desencadearam as revoluções conhecidas como Reforma e Contra-Reforma.

As transformações na religião oportunizaram mais avanços no campo da ciência, pois o protestantismo, proveniente da Reforma, estimulava a pesquisa científica. Ronan (2001c, p. 11) 
afirma que "o estímulo científico foi causado pelo desejo de usar a descoberta para criar uma figura do Universo ordeira e coerente com a finalidade de descobrir ainda mais o trabalho de Deus".

Outro campo que sofreu muitas influências na Renascença foi o campo da ciência, mesmo sem possuir esse nome. As principais mudanças ocorridas nesse período foram na astronomia, principalmente com a obra de Copérnico. Ele sugeriu que o Sol estava no centro do Universo, e não a Terra. Esse fato transformou a astronomia e trouxe revoluções no modo de ver a ciência, não mais colocando a autoridade acima da observação (RONAN, 2001c).

Continuando a jornada na história da ciência, chegamos ao período onde ela floresceu. Foram tantas mudanças na forma de se fazer ciência, que esse período, do final do século XVI ao século XVIII, ficou conhecido como Revolução Científica e a filosofia natural passou a ser chamada de ciência.

Galileu Galilei foi um personagem de muita importância no período. Seu trabalho é paradigmático, o que significa que, a partir de sua obra sobre a queda dos corpos, as teorias aristotélicas sobre o movimento dos corpos tornam-se impossíveis de serem retomadas (CHASSOT, 2004). Galileu usou o telescópio para fazer observações do Universo e todas as suas observações mostravam fortes evidências em favor da teoria heliocêntrica de Copérnico.

Todas essas revoluções entravam em conflito com a visão tradicional da Igreja. Assim, perseguições e contendas ocorriam, inaugurando, dessa forma, a tese do conflito entre ciência e religião. Galileu foi condenado pela Inquisição e passou seus últimos anos em reclusão.

Porém, existe a necessidade de considerar alguns pontos acerca do julgamento de Galileu. Em primeiro lugar, a ciência, assim como a Igreja, considerava como correta a hipótese do geocentrismo, portanto, quando Galileu endossa a teoria de Copérnico, a astronomia entra em conflito, as bases da ciência estão sendo alteradas. Outro fato a ser considerado é que Copérnico, o criador do heliocentrismo, não foi condenado pela Igreja. E por último, devido a Reforma Protestante, a Igreja não poderia ser desprestigiada, e as descobertas de Galileu afetavam suas bases. Assim, uma atitude precisou ser tomada (HARRISON, 2017). Dessa forma, podemos perceber que a condenação de Galileu não foi apenas por causa de suas descobertas científicas, mas motivos políticos também influenciaram as atitudes tomadas pela Igreja.

As origens do método científico se dão com Bacon. Em sua filosofia, ele propõe que "para se conhecer a natureza, é preciso observar (acumular) os fatos, classificá-los e determinar suas causas." (CHASSOT, 2004, p. 150). As ideias de Descartes defendiam esse novo modelo de ciência. Ele considerou que os erros encontrados a partir da nova forma de se produzir conhecimento científico são provenientes da falta de um método. Sobre o método de Descartes, Marcondes (2010, p. 162) abona que

O método é um caminho, um procedimento que visa garantir o sucesso de uma tentativa de conhecimento, da elaboração de uma teoria científica. Um método se constitui basicamente de regras e princípios que são as diretrizes desse procedimento.

A expressão filosófica mais conhecida dele é "Cogito, ergo sum” (Penso, logo existo), o objetivo principal dessa expressão é estabelecer os fundamentos do conhecimento. Através dela, "Descartes justifica o poder da razão de perceber o mundo por meio de ideias claras e 
distintas. "(CHASSOT, 2004, p. 151).

Com os estudos de Newton, toda a ciência dos corpos em movimento foi reescrita, ele completou a obra de muitos estudiosos, incluindo Brahe, Galileu e Kepler. Com a descoberta da atração universal, "segundo a qual cada corpo do Universo atrai todos os outros" (RONAN, 2001c, p. 99), as bases da física foram reconstruídas, pois não mais havia um conjunto de leis para explicações do comportamento dos corpos celestes e outro conjunto de leis para governar os terrestres. A partir de Newton, a física passa a ser universal (RONAN, 2001c).

O pensamento moderno surge das crises enfrentadas nesse período, por exemplo, a autoridade da Igreja foi contestada pela Reforma, a autoridade das teorias de Aristóteles foi contestada pelos novos pensadores, como Copérnico e Galileu (MARCONDES, 2010). Assim, esse período foi marcado por grandes mudanças filosóficas. O que era considerado filosofia natural passa a ter um método de sistematização, o que acarreta a consolidação da ciência moderna, no século XIX.

\section{A consolidação da Ciência}

O início da história da ciência com os gregos antigos, seu enfraquecimento durante a Idade Média, sua retomada durante o Iluminismo, sua ascensão com a Revolução Científica e sua consolidação no século XIX são marcos históricos importantes. O que no início era chamado de filosofia, feita pelos filósofos naturais, passa, então, a ser denominado de ciência, e seus agentes, os cientistas.

Os grandes avanços da ciência, no século XIX, demandaram a formação de sociedades científicas especializadas. Uma das mais importantes foi a Associação Britânica para o Progresso da Ciência, surge dela, a palavra cientista para designar as pessoas que buscam o conhecimento nessa área. As associações eram as responsáveis para divulgar o trabalho dos cientistas, surgem os periódicos, escritos com um padrão específico, a linguagem científica, que disseminavam os conhecimentos. Ronan (2001d, p. 7) afirma que "um de seus efeitos foi incrementar um interesse já amplo pela ciência."

Um trabalho paradigmático foi a teoria da evolução, proposta por Darwin. Seu livro, A origem das espécies, foi o mais vendido no ano de 1859. O conceito de evolução tornou-se cientificamente respeitável e acarretou uma onda de protestos provenientes de pessoas que não queriam aceitar as provas e daqueles que se baseavam no literalismo bíblico. O caso do julgamento de Galileu e a proposição da teoria da evolução de Darwin são os dois principais casos históricos que marcam o surgimento da ideia de um conflito entre ciência e religião.

Ao observar a história da ciência no século XIX, percebemos grandes avanços nos mais diferentes ramos desse conhecimento. Porém, no século XX, observamos um desenvolvimento ainda mais proeminente. Além do número de pessoas se empenhando na busca de conhecimentos científicos, os equipamentos estão cada vez mais poderosos e sofisticados, o que acarreta resultados mais fabulosos. 
Ronan (2001d, p. 125) nos ensina que

uma das lições óbvias a ser aprendida com a história das realizações científicas é que nenhuma teoria sobrevive para sempre e que, muitas vezes, quando as coisas parecem solidificadas, novas observações e novas ideias a substituem por conceitos atualizados.

Agora, no início de um novo século, percebemos a continuidade dos avanços da ciência e uma dependência, cada vez mais, de sua aplicação. A sociedade está impregnada de produtos que são frutos do pensamento científico.

Após percorrer todo esse período histórico e chegar ao século XXI, podemos compreender que a ciência é um campo de conhecimento que possibilita a construção de leis e teorias que regem os fenômenos naturais. Sua aplicação, sob a forma de tecnologia, por um lado, favorece a vida, por outro, causa problemas (ambientais, sociais, entre outros). Destacamos, assim, a relevância de conhecer esse tão importante ramo do conhecimento.

Retomando a ideia de buscar construir uma definição para ciência, é possível perceber que não existe um conceito universal e atemporal da ciência ou um método científico que resolva qualquer problema encontrado. Inclusive este texto não pode ser considerado como pronto e acabado. A ciência está em plena construção. Dessa forma, a busca por conhecimento deve ser a base de qualquer pessoa que se empenhe nesse ramo.

A vida está imbuída de saberes científicos. O ser humano tem utilizado a aplicação dos conhecimentos da ciência para melhorar sua qualidade de vida. A longevidade aumenta devido ao desenvolvimento de medicamentos e tratamento para inúmeras doenças. A divulgação do conhecimento está aquecida, a todo o momento, podemos ter acesso às mais diversas informações. Os seres humanos estão imersos na aplicação dos conhecimentos científicos, mesmo sem ter plena consciência disso, até porque conhecimento científico é diferente de informação disseminada.

É importante ressaltar que a má aplicação dos conhecimentos científicos pode acarretar prejuízos. Muitas vezes, a tecnologia é utilizada em favor de um grupo de pessoas em detrimento de outro. Inúmeros casos podem ser usados como exemplo desse fato: uso de armas cada vez mais poderosas, incluindo a bomba atômica; uso de defensivos agrícolas; exploração do solo para retirada de minérios; produção de drogas; o descarte do humano em detrimento da máquina, entre muitos outros.

Em todos esses exemplos, podemos notar que existem pelo menos dois lados. Há aqueles que defendem o uso de defensivos agrícolas por conta da necessidade de produção de alimentos para atender uma população cada vez maior. A crítica advém do fato de que essa produção não sustenta a população mundial como deveria e que, concomitante a isso, os defensivos agrícolas acabam prejudicando a saúde do ser humano e do próprio ambiente.

Sobre a extração de minérios, por exemplo, é claro que trazem benefícios para a população. Mas, todos nós ficamos estarrecidos com o rompimento da barragem da cidade de Brumadinho - MG, que ceifou a vida de muitas pessoas e condenou todo o seu ambiente natural. Há que se encontrar culpados para isso? Certamente a gestão administrativa da empresa em questão deve ser responsabilizada. E o papel da ciência? Os problemas, muitas vezes, se referem 
ao uso inadequado do conhecimento científico pelos seres humanos.

Granger (1994, p. 20) nos deixa um questionamento perturbador:

deve-se deixar à ciência em marcha a liberdade total de explorar todos os seus caminhos de pesquisa, sabendo que seus resultados poderão eventualmente ser utilizados contra o que reconhecemos ser o bem coletivo?

Assim, é necessário ter ética e dedicação ao formar uma concepção de ciência e de sua técnica. Muitos dispensam uma fé cega na ciência e, a concebem como salvadora, a única forma de melhorar o mundo. Consideram a ciência como um saber superior a todos os outros.

A confusão se instaura nesse sentido, pois a ciência é capaz de lidar com várias questões teóricas e problemas práticos, desde que estejam bem formulados, e ao problematizar essas questões, consegue trazer aspectos de solução, o que é confundido muitas vezes, por um saber superior aos outros. Nessa perspectiva, cientistas e técnicos são considerados pessoas que regem todos os processos humanos e sociais.

O saber científico - relevante para a continuidade e o desenvolvimento da humanidade - não deve, a partir de nossa ótica, ser destacado como um saber salvador. Essa ideia é difícil de compreender porque o mundo está cada vez mais dependente da ciência. Vale lembrar que a ciência pode, ao trazer as respostas, provocar outros problemas subsequentes.

$\mathrm{Na}$ busca de auxiliar uma melhor compreensão acerca do trabalho científico, Gil-Perez et al. (2001) trazem algumas características que devem ser consideradas ao estudar ciência. Expomos, de forma resumida e com algumas contribuições, tais características:

1- A recusa da ideia de "Método científico" como um conjunto de regras mecânicas para fazer ciência. Existe uma gama de metodologias validadas e aplicadas à construção dos conhecimentos científicos;

2- A percepção de que os conhecimentos científicos não são apenas resultados testados empiricamente de hipóteses dedutivas para a resolução de um problema. Os problemas que fazem com que a ciência elabore novas teorias são provenientes de situações confusas, eles não surgem prontos.

3- O reconhecimento do papel da investigação e valorização das hipóteses. São as hipóteses que guiam a resolução dos problemas. A busca das evidências experimentais irá indicar a necessidade ou não de novas hipóteses, elas são colocadas à prova. Assim, a construção dos conhecimentos científicos não está baseada em certezas, mas em tentativas de respostas.

4- A procura por uma coerência global. A dúvida sempre acompanha o trabalho científico. Os resultados obtidos devem ser revisados, utilizando outros caminhos. Assim, é possível perceber semelhanças entre os resultados obtidos a partir de diversos caminhos. O trabalho científico deve conduzir à coerência e globalidade, elaborando leis e teorias que se apliquem ao maior número de fenômenos possíveis.

5- A compreensão do caráter social do desenvolvimento científico, realizado por homens e mulheres da ciência, influenciado pelos aspectos históricos, sociais, culturais e políticos e conectado a todos os outros aspectos da sociedade. 
Observando esse percurso delineado da história da ciência, podemos notar que esse campo de conhecimento está em pleno processo de construção, a cada dia surgem novas leis, novas teorias, novas metodologias, novos cientistas, a lista continua.

Portanto, devemos considerar que a ciência ajuda a resolver problemas, explica os fenômenos, possibilita novos conhecimentos, mas, não podemos afirmar que ela é detentora de todas as respostas, uma vez que nem todas as perguntas foram formuladas. Devemos valorizar o campo da ciência, porém, sem menosprezar outros campos de conhecimento, pois tudo colabora com a compreensão do mundo.

\section{Interação entre Ciência e Religião}

Talvez pareça atrevido ou despropositado abordar o tema religião dentro de uma proposta de trabalho que visa a melhoria no ensino de ciências naturais. Para evitar possíveis distorções no caminho que pretendemos trilhar para construção dessa pesquisa, tentaremos adiante, de forma respeitosa, tolerante e acadêmica, construir uma possibilidade de entendimento do que seja religião.

Japiassu e Marcondes (2006, p. 239) definem religião como sendo "um conjunto cultural suscetível de articular todo um sistema de crenças em um Deus ou num sobrenatural e um código de gestos, de práticas e de celebrações rituais". As pessoas constroem relações entre as tradições, movimentos, comunidades, crenças e práticas com o que chamam de religião. Cada religião acredita possuir a verdade, estando sempre baseada em uma fé ou em crenças.

Ao definir religião, devemos ter o cuidado para não favorecer um tipo de religião em detrimento de outro. McGrath (2005, p. 44) afirma "que todas as religiões nada mais são do que respostas locais culturalmente condicionadas à mesma realidade suprema transcendente." Porém, nem todas as religiões dizem as mesmas coisas. Religião seria o "modo mais comum de caracterizar atitudes, crenças e práticas ligadas ao sagrado e ao sobrenatural. " (HARRISON, 2017, p. 23).

Em um mundo cada vez mais dependente da tecnologia e da aplicação do conhecimento científico, não devemos acreditar que estaremos livres das coisas das religiões, pois:

por mais secularizado ou desencantado que tenha se tornado nosso mundo, nosso conhecimento a respeito dele está sempre impregnado de crença e sagrado. Porque onde houver ser humano haverá crença e manifestação do sagrado. (JAPIASSU, 2005, p. IIO).

Durante os estudos, percebemos que falar de um relacionamento entre ciência e religião pode acarretar muita confusão, haja vista que ambos os campos possuem uma gama de definições e classificações. Como o presente texto se refere ao trabalho de conclusão de um mestrado profissional em ensino de ciências naturais, escolhemos tal ciência para escopo de discussão.

A religião cristã foi escolhida, pois é o tipo de religião que está mais profundamente envolvida na interação com as ciências naturais. Harrison (2006), afirma que a religião cristã pode ser considerada como caso paradigma, pois sua relação com a ciência assume uma posição diferenciada durante o período conhecido como Iluminismo. 


\section{MODELOS DE RELACIONAMENTO ENTRE CIÊNCIA E RELIGIÃO}

A organização dos modelos de relacionamento está baseada nas ideias de que: ciência e religião são inimigas, pois há pessoas que estão incentivando a guerra entre os campos; são estranhas, pois a ciência lida com as relações entre as causas e a religião lida com o sentido e propósito da vida; e são parceiras, pois sabem que cada campo não é detentor de todas as respostas, portanto, são interdependentes (BARBOUR, 2004).

Partindo dessas características, Barbour organiza o relacionamento entre ciência e religião a partir de quatro perspectivas: conflito, independência, diálogo e integração. Tais perspectivas surgem devido ao fato de que "cada tipo compreende diversas variantes que diferem significativamente, mas essas variantes possuem traços em comum, o que lhes permite serem agrupadas conjuntamente." (BARBOUR, 2004, p. 21).

Apresentaremos a seguir, os quatro modelos de relacionamento organizados por Barbour (2004). Incluímos no texto, algumas contribuições feitas por outros autores que também estudam o relacionamento entre os campos da ciência e da religião.

\section{MODELO DO CONFLITO}

Essa tipologia considera que os campos da ciência e da religião estão em oposição fundamental, que não tem nada em comum, que buscam provar ser melhor do que o outro e que sempre foi assim. Portanto, não existe possibilidade de relacionamento entre os campos, assim, um cientista não pode professar uma religião e um religioso não pode estudar/produzir ciência.

Alexander (2007, p. 2) afirma que "o conflito ocorre quando a ciência ou a religião adotam atitudes expansionistas, reivindicando responder a questões que pertencem ao outro domínio de inquirição. " Ou seja, quando a ciência tenta responder a questões pertencentes à esfera da religião e vice-versa.

Os materialistas científicos e os literalistas bíblicos incentivam ainda mais o estabelecimento do conflito entre os campos. O modelo do conflito está sustentado, principalmente, nos episódios de Galileu com a Igreja e na suposta oposição da Igreja com a teoria da evolução de Darwin.

Observando as características apresentadas, percebemos que ao considerarmos apenas o fato de que a ciência é objetiva, aberta, universal, cumulativa e progressiva e as tradições religiosas são subjetivas, fechadas, paroquiais, acríticas e resistentes à mudança não poderemos ter nenhum relacionamento, apenas conflitos.

Apesar de todos esses fatores apresentados, Alexander (2007, p. 2) reitera que "nenhum historiador da ciência crê que o modelo do conflito forneça uma estrutura abrangente e satisfatória para explicar as interações históricas entre ciência e religião. " Portanto, a busca de conhecimento deve estar sempre presente para evitar conclusões errôneas.

\section{MODELO DA INDEPENDÊNCIA}

O modelo da independência afirma que ciência e religião não podem se relacionar pois 
correspondem a campos de conhecimento totalmente diferentes. Barbour (2004, p. 32) afirma que "é possível discriminá-las de acordo com as perguntas que fazem, com os domínios a que se referem e com os métodos que empregam."

Nessa perspectiva, evidenciamos algumas características dicotômicas: a ciência explica dados objetivos, a religião se preocupa com a existência da ordem e beleza no mundo e as experiências da vida interior; a ciência quer saber sobre o como e a religião sobre o porquê, o sentido e a finalidade; a ciência se baseia na coerência lógica e na adequação experimental e a religião se baseia na autoridade de Deus e na revelação; a ciência faz previsões qualitativas que podem ser testadas experimentalmente, a religião usa linguagem simbólica e analógica para conhecer e explicar o Deus transcendente (BARBOUR, 2004).

Assim, cientistas e religiosos são livres para executar suas tarefas sem interferência dos campos opostos. Os dois campos de conhecimento colaboram com o entendimento dos fenômenos que ocorrem no mundo, cada um atendendo as suas especificidades. Harrison (2017, p. 32) diz que "ciência é hábito intelectual; religião, como as demais virtudes, é hábito moral." Portanto, nesse modelo não existe conflito entre os campos por não haver nenhuma possibilidade de relacionamento entre eles.

Alexander (2007) expõe críticas a esse modelo de interação: a história da ciência evidencia que muitas das ideias construídas por importantes cientistas foram influenciadas por suas crenças religiosas; a realidade a que se referem ciência e religião é a mesma; e as atividades tanto da ciência quanto da religião são profundamente humanas.

\section{MODELO DO DIÁLOGO}

Para haver a possibilidade dessa tipologia, é necessário que haja uma relação de respeito mútuo entre os campos da ciência e da religião. "O diálogo pode emergir da consideração dos pressupostos da especulação científica, ou da abordagem das semelhanças entre os métodos da ciência e da religião, ou da análise dos conceitos de uma área análogos aos da outra. " (BARBOUR, 2004, p. 38).

Segundo Barbour (2004), o modelo do diálogo está baseado em duas situações: Pressupostos e questões-limite e Paralelos metodológicos e conceituais.

Parte-se do pressuposto de que o mundo é inteligível e tem uma ordem, tal afirmação é proveniente do pensamento grego e do pensamento bíblico, ela ajuda a explicar o motivo da ciência moderna ter surgido no Ocidente (BARBOUR, 2004). Assim, a ciência nos ajuda a compreender os fenômenos que ocorrem na natureza. As leis e teorias científicas possibilitam a organização e o planejamento.

Porém, existem algumas questões que ainda não foram resolvidas pela ciência, tais questões são chamadas de questões-limite. Uma questão-limite popular é: Por que existe um Universo? A ciência afirma que o Universo tem uma ordem e que é contingente, ou seja, suas leis e condições iniciais não eram necessárias. Podemos nos perguntar o motivo desta contingência e inteligibilidade. A ciência ainda não tem tal resposta, mas os teólogos dizem que Deus é a base racional e criativa da ordem contingente do Universo (BARBOUR, 2004). 
O uso de analogias e modelos pode evidenciar uma aproximação entre os campos. $\mathrm{Na}$ ciência, os modelos são utilizados para imaginar o que não pode ser observado. A religião também se apoia em metáforas e modelos para evidenciar suas características. As crenças da religião não podem ser testadas empiricamente, como as da ciência, mas os critérios de coerência, abrangência e fecundidade podem ser aplicados aos dois campos (BARBOUR, 2004).

Outro paralelo metodológico afirma que as teorias da ciência são dependentes dos paradigmas vigentes, assim como as tradições religiosas partilham um paradigma comum. Além disso, a condição do observador deve ser considerada, tanto na ciência quanto na religião, o observador influencia o objeto a ser observado.

Neste modelo do diálogo, é fundamental o reconhecimento de diferenças nos métodos entre ciência e religião, porém, há também a necessidade de considerar a existência de paralelos significativos entre os métodos dos campos. Dessa forma, a possibilidade do diálogo significativo entre os campos é real (BARBOUR, 2004).

\section{MODELO DA INTEGRAÇÃO}

O modelo da integração surge de uma reformulação mais ampla e sistemática das ideias apresentadas no modelo do diálogo. Alexander (2007) considera que "este modelo sustenta que a ciência e a religião se referem à mesma realidade a partir de diferentes perspectivas, provendo explanações complementares, de modo algum, rivais. " (ALEXANDER, 2007, p. 4).

Barbour (2004) fomenta três versões distintas de integração: a teologia natural, a teologia da natureza e a síntese sistemática.

Na versão da teologia natural "alega-se que a existência de Deus pode ser deduzida (ou é fortalecida) a partir dos indícios de um planejamento na natureza, dos quais a ciência nos tornou mais conscientes. " (BARBOUR, 2004, p. 43-44). Essa versão parte de dados científicos para explicar o mundo. As pessoas que defendem o argumento do planejamento afirmam que a crença em um Planejador é tão plausível quanto outros argumentos.

A próxima versão da tese da integração é a teologia da natureza. Ela "parte de uma tradição religiosa, baseada na experiência religiosa e na revelação histórica. " (BARBOUR, 2004, p. 47). O referido autor salienta a necessidade de algumas tradições religiosas se reformulem à luz da ciência atual. Assim, as doutrinas teológicas devem estar em harmonia com as teorias científicas.

Porém, Japiassu (2005) nos alerta que tal integração entre os campos não pode ser simplista, pois:

por mais vinculados e complementares que possam parecer os saberes científicos e religiosos, de uma coisa não podemos nos esquecer: precisamos reconhecer na ciência e na religião dois modos distintos de pensar (e agir), não só quanto a seus objetivos, mas a seus meios (JAPIASSU, 2005, p. I60).

A última versão que constitui o modelo da integração é a síntese sistemática. Barbour (2004, p. 50) infere que "uma integração mais sistemática pode ocorrer se ambas, ciência e reli- 
gião, contribuírem para uma visão coerente de mundo, elaborada numa metafísica includente".

Qualquer um dos quatro modelos apresentados não será suficiente para explicar um relacionamento tão complexo quanto o relacionamento entre ciência e religião. Portanto, não somos reducionistas para indicar a escolha de um desses modelos. Mas intentamos evidenciar que é possível relacionar os campos e com isso, melhorar o ensino de ciências, principalmente quando os professores são questionados sobre essa relação ou durante os conteúdos considerados como polêmicos.

\section{A ESCOLHA DO LIVRO PARADIDÁTICO}

Para fomentar o diálogo entre os campos da ciência e da religião, construímos um livro paradidático intitulado: Ciência e Religião no Ensino de Ciências Naturais: Pode isso? O material está dividido em três capítulos: 1- Ciência: o que eu sei sobre ela?; 2- Cosmovisão: a visão que eu tenho do mundo; e 3- Parceria entre ciência e religião no ensino de ciências: Pode isso? Apresentamos a seguir, uma breve explicação dos conteúdos de cada capítulo.

O primeiro capitulo apresenta a ciência. Iniciamos o texto com a proposição de definições para esse campo de conhecimento. Em seguida, apresentamos um breve resumo sobre sua história, pois acreditamos que a história influencia na constituição da ciência enquanto campo de conhecimento. Abordamos também, mesmo que superficialmente, a epistemologia da ciência e apresentamos o cientificismo. Terminamos o texto apresentando as visões deformadas do trabalho científico e as atitudes que devem ser tomadas para suplantá-las.

O segundo capitulo aborda a cosmovisão, que se refere à forma como vemos e interpretamos o mundo ao nosso redor, ou seja, um conjunto de crenças. Apresentamos alguns tipos de cosmovisão (teísmo cristão, naturalismo, niilismo, deísmo, pós-modernismo, dentre outras) e sugerimos a busca por mais conhecimento acerca da cosmovisão pessoal.

O terceiro capitulo discorre sobre a parceria entre ciência e religião no ensino de ciências. Começamos o texto definindo o que é religião e apresentamos um breve resumo de sua história. Em seguida, discutimos as origens da ideia de um conflito entre esses campos. Finalmente, apresentamos a série de quatro modelos (Modelo do conflito, Modelo da independência, Modelo do diálogo e Modelo da integração) propostos por Barbour (2004).

Concluímos, assim, o produto educacional e esperamos que ele colabore com um ensino de ciências naturais que valorize outros campos de saberes, que seja tolerante com a diversidade a religiosa, que leve em conta a história, que se preocupe com a coerência global e que forme pessoas mais conscientes de seu papel frente ao mundo.

\section{RESULTADOS E DISCUSSÕES}

Nesta seção, apresentamos os resultados obtidos através da aplicação da metodologia da pesquisa. Para responder à pergunta norteadora, construímos um questionário de partida, no qual, os sujeitos da pesquisa puderam exprimir suas opiniões acerca da relação entre ciência e religião e, para validar o produto educacional, os sujeitos responderam ao questionário final.

Nóbrega, A.; Soares, E. - O Desenvolvimento Profissional Docente entre Ciência e Religião. 
Para propiciar a aplicação da metodologia organizamos uma oficina chamada "CIÊNCIA E RELIGIÃO DIALOGANDO? ". A oficina aconteceu durante os encontros de formação continuada para os professores no Liceu Cuiabano. Nela, os professores puderam realizar a leitura completa do livro paradidático e responder aos dois questionários.

Uma das perguntas que compôs o questionário de partida foi: Durante suas aulas, você já foi questionado (pelos alunos) sobre a relação entre os conteúdos trabalhados e a religião? Ela ainda solicitava que os sujeitos que deram respostas positivas, explicassem como responderam ao questionamento. Dos 13 (treze) sujeitos, 8 (oito) disseram já ter sido questionados e 5 (cinco) disseram não ter sido questionados.

Aplicamos os procedimentos de ATD sobre as explicações que os sujeitos deram. A partir da unitarização, emergiram seis categorias, são elas: Questões-limite; A ciência tem um método; A religião tem um método; Evolucionismo versus criacionismo; Os dois campos colaboram com a compreensão do mundo; e Incoerência entre os campos.

Observando, pois, as compreensões construídas pelos sujeitos, as nossas compreensões e a fundamentação teórica, alimentamos o "caldeirão de ideias" (MORAES; GALIAZZI, 2011, p. 198) e construímos um metatexto que organiza todas essas compreensões.

Sendo assim, quando questionados sobre a relação entre os conteúdos trabalhados e a religião, os professores demonstram que os campos da ciência e da religião são distintos, no entanto, os dois podem colaborar com uma melhor compreensão do mundo.

Ao explicar o que é ciência, os professores sustentam que a ciência possui uma metodologia que leva à construção de teorias e leis. Compreendem, portanto, que a ciência é um campo de conhecimentos metódico e rigoroso que explica, racional e objetivamente, os fenômenos da natureza.

A necessidade de conhecer o pensamento científico sobre o evolucionismo foi ressaltada por um dos professores. Alguns cientistas e líderes religiosos sustentam a ideia de que a teoria da evolução é incompatível com as crenças religiosas. Porém, o evolucionismo, enquanto teoria científica, não exige um abando de crenças. Além disso, a teologia natural busca provar racionalmente a existência de Deus (MCGRATH, 2017). Assim, não é necessário negar as questões de crenças ao ensinar o evolucionismo.

Ao afirmar que a ciência ainda não possui uma resposta definitiva sobre a origem do Universo ou sobre a existência ou não de Deus, os professores inferiram a ideia acerca das questões-limites, aquelas questões que se referem "às fronteiras metodológicas e conceituais, bem como espaciais e temporais." (BARBOUR, 2004, p. 39).

Observando com cuidado as respostas dos sujeitos da pesquisa, podemos inferir que, mantendo a distinção entre os campos da ciência e da religião, um diálogo entre eles se torna possível. Barbour (2004, p. 72) afirma que:

Os defensores do diálogo afirmam que a ciência tem pressupostos e levanta questões-limite que a própria ciência não é capaz de responder. As tradições religiosas argumentam esses pensadores, podem sugerir respostas possíveis para essas questões, 
sem violar a integridade da ciência.

Assim, uma resposta para essa questão é que os campos da ciência e da religião podem conviver, uma vez que cada um deles é responsável por explicações em áreas distintas. Havendo respeito e tolerância, os campos podem conversar, com o intuito de conhecer o mundo, de complementar o conhecimento e entender a complexidade dos fenômenos que estão à nossa volta.

Após a análise dos questionários, convidamos quatro professores para participar da entrevista. Nelas, eles responderam a 17 (dezessete) perguntas referentes à compreensão de ciência, do relacionamento entre ciência e religião e sobre o livro paradidático.

Uma das perguntas realizadas foi: Qual a contribuição do relacionamento entre ciência e religião para o ensino da sua disciplina? Essa pergunta se refere ao problema principal deste trabalho. A hipótese inicial dizia que as ciências podem ser ensinadas nas escolas de uma forma diferente, mais engajada e menos dogmática, rompendo com as visões deformadas da ciência (GIL-PEREZ et. al., 2001) e que sua aproximação com a religião não a torna menos importante.

A unitarização efetuada nas respostas dadas a essa questão, nos remeteu a constituição de 3 (três) categorias: os campos são complementares, o relacionamento entre ciência e religião ajuda na compreensão dos mais diversos processos estudados pela ciência e ajuda o professor a tomar decisões, se posicionar, frente aos embates de sua profissão.

Na triangulação dos conhecimentos produzidos, ou seja, a partir das respostas dos professores entrevistados, da fundamentação teórica e dos conhecimentos adquiridos durante todo o processo, construímos o metatexto apresentado em seguida:

A história da ciência evidencia vários momentos em que os campos da ciência e da religião, conforme compreendidos atualmente, colaboraram com compreensão dos fenômenos da natureza. Portanto, essa perspectiva pode romper com uma visão de ciências "aproblemática e ahistórica (portanto, dogmática e fechada)" (GIL-PEREZ et al., 2001, p. 131).

Além disso, devemos conceber o caráter social do desenvolvimento científico, realizado por homens e mulheres da ciência, influenciado pelos aspectos históricos, sociais, culturais e políticos e conectado a todos os outros aspectos da sociedade (GIL-PEREZ et al., 2001). Munidos desse tipo de conhecimento podemos usar os conhecimentos da ciência para compreender mais profundamente os fenômenos naturais e tomar posição perante a eles.

Um dos sujeitos discorreu que a religião norteia sua vida, que o ajuda a fazer escolhas, a caminhar. Com relação à sua vida profissional, ele entende que "não é só a base racional de uma formação que me faz querer ser um bom profissional, é a bagagem que eu trago como pessoa, a bagagem que eu trago naquilo que eu aprendi, naquilo que eu cresci".

Outra questão interpelada foi: Qual sua opinião sobre o livro paradidático? Um professor disse que o livro paradidático ficou leve, no sentido de trazer discussões que proporcionam grandes polêmicas, de forma cuidadosa e que remete a reflexões. Apesar de leve e sutil, ele afirma que o texto é direto, que ressalta a importância tanto da ciência quanto da religião. Outro professor afirmou que o material é uma ferramenta interessante pois ajuda na compreensão de que ciência e religião não são divergentes, mas sim, complementares. 


\section{CONSIDERAÇÕES FINAIS}

Este trabalho possibilitou a percepção da necessidade que o professor tem em se manter em constante desenvolvimento profissional. Os cursos de formação inicial colaboram com a construção de conhecimentos científicos e pedagógicos e os cursos de formação continuada promovem uma renovação dos conhecimentos, porém, o professor pode aprender em outros momentos também.

Compreendemos que o professor é fruto de várias experiências e, para o exercício de sua profissão, carrega todos esses conhecimentos. A profissão docente requer certo grau de exposição, uma vez que os alunos estão em contato direto com os professores. Durante as aulas, os alunos fazem muitos questionamentos, não apenas referentes ao conhecimento científico, mas também sobre outros saberes. Temas que podem ser considerados polêmicos, por exemplo a entropia, a teoria quântica, a teoria da evolução, desenvolvimento embrionário, entre outros, promovem uma demanda de perguntas que envolvem conhecimentos que extravasam a ciência e vão em direção à religião.

Um professor que se percebe em desenvolvimento profissional, consegue, a partir de sua cosmovisão, proporcionar um diálogo ético, autêntico, tolerante, rigoroso [...] e construtivo entre ciência e religião a partir de sua prática pedagógica.

O livro paradidático "Ciência e Religião no Ensino de Ciências Naturais: Pode isso?”, segundo a perspectiva dos sujeitos de pesquisa, colabora com a formação de professores, pois traz fundamentação referente aos dois campos de conhecimento. Apontado como lúdico e de escrita leve, porém direta, o livro paradidático favoreceu a leitura e a curiosidade dos participantes.

A análise qualitativa promoveu a compreensão de que o livro paradidático atingiu seus objetivos e que pode promover um ensino de ciências naturais de forma mais cuidadosa. Pode ainda, auxiliar no entendimento da importância de conhecer a cosmovisão dos sujeitos envolvidos na prática docente e possibilitar conhecimentos no campo da religião e dos modelos mentais sobre o relacionamento entre ciência e religião, apresentando outras formas de relacionamento, superando, inclusive, o modelo de conflito entre os campos.

Portanto, o relacionamento entre ciência e religião pode contribuir com o ensino de ciências naturais, haja vista que a história evidencia vários momentos em que os dois campos colaboraram com a compreensão dos fenômenos da natureza. Além disso, para apreender o caráter do desenvolvimento científico, é relevante perceber que outros aspectos influenciam nesse saber, os aspectos históricos, sociais, políticos, culturais e religiosos.

Considerando os anseios e as limitações de uma pesquisa de mestrado, nossa proposta apontou ainda para a necessidade de superação de muitos equívocos construídos ao longo da formação inicial, dentre os quais, a ênfase na impossibilidade da existência de um diálogo entre os campos mencionados. 


\section{REFERÊNCIAS}

ALEXANDER, Denis R. Modelos para relacionar ciência e religião. The Faraday Institute for Science and Religion. Tradução: Guilherme V. R. de Carvalho. set. 2007. Disponível em: $<$ http://www.cristaosnaciencia.org.br/recursos/parturient-egestas-vehicula/ $>$. Acesso em: 23 jul. 2018.

ANDRÉ, Marli. Formação de professores: a constituição de um campo de estudos. Educação, Porto Alegre, v. 33, n. 3, p. I74-I8I, set/dez 2010.

BARBOUR, Ian G. Quando a ciência encontra a religião: Inimigas, estranhas ou parceiras. Tradução: Paulo Salles. São Paulo: Cultrix, 2004.

BOGDAN, R. C.; BIKLEN, S. K. Investigação qualitativa em educação: uma introdução à teoria e aos métodos. Portugal: Porto Editora, I994.

CHALMERS, Alan Francis. O que é ciência afinal? Tradução: Raul Filker. São Paulo: Brasiliense, 1993.

CHASSOT, Attico. A ciência através dos tempos. 2. ed. São Paulo: Moderna, 2004.

DAY, Christopher. Desenvolvimento Profissional de Professores Os desafios da aprendizagem permanente. Tradução: Maria Assunção Flores. Porto, Portugal: Porto Editora, $200 I$.

GIL-PEREZ, D.; MONTORO, I. F.; ALIS, J. C.; CACHAPUZ, A.; PRAIA, J. Para uma imagem não deformada do trabalho científico. Ciência e Educação, Bauru, v. 7, n. 2, p. I25-I53, 200 I.

GONSAlVES, Elisa Pereira. Conversas sobre Iniciação à Pesquisa Científica. 4. ed. Campinas: Editora Alínea, 2007.

GRANGER, Gilles-Gaston. A ciência e as ciências. Tradução: Roberto Leal Ferreira. São Paulo: Editora Unesp, I994.

HARISSON, Peter. "Ciência" e "Religião": Construindo os Limites. Revista de Estudo da Religião - REVER, São Paulo, 2006.

HARISSON, Peter. Os territórios da ciência e da religião. Tradução: Djair Dias Filho. Viçosa, MG: Ultimato, 2017.

JAPIASSU, Hilton. Ciência e destino humano. Rio de Janeiro: Imago, 2005.

JAPIASSU, H.; MARCONDES, D. Dicionário básico de filosofia. 4. ed. Rio de Janeiro: Jorge Zahar Ed., 2006.

MARCELO GARCIA, Carlos. Formação de professores: para uma mudança educativa. 
Tradução: Isabel Narciso. Porto, Portugal: Porto Editora, I999.

MARCELO, Carlos. Desenvolvimento profissional docente: passado e futuro. Sísifo - Revista das Ciências da Educação, n. 08, p. 7-22, jan/abr 2009.

MARCONDES, Danilo. Iniciação à história da filosofia: dos pré-socráticos a Wittgenstein. 6 . ed. Rio de Janeiro: Jorge Zahar Ed., 200I.

MCGRATH, Alister E. Fundamentos do diálogo entre ciência e religião. Tradução: Jaci Maraschin. São Paulo: Edições Loyola, 2005.

MORAES, R.; GALIAZZI, M. C. Análise Textual Discursiva. 2. ed. Ijuí, RS: Ed. Unijuí, $20 I I$.

RONAN, Colin A. História ilustrada da ciência da Universidade de Cambridge. Volume I: das origens à Grécia. Tradução: Jorge Enéas Fortes. Rio de Janeiro: Jorge Zahar Ed., 200I. (a)

RONAN, Colin A. História ilustrada da ciência da Universidade de Cambridge. Volume 2: Oriente, Roma e Idade Média. Tradução: Jorge Enéas Fortes. Rio de Janeiro: Jorge Zahar Ed., 200I. (b)

RONAN, Colin A. História ilustrada da ciência da Universidade de Cambridge. Volume 3: da Renascença à revolução científica. Tradução: Jorge Enéas Fortes. Rio de Janeiro: Jorge Zahar Ed., 200I. (c)

RONAN, Colin A. História ilustrada da ciência da Universidade de Cambridge. Volume 4: A ciência nos séculos XIX e XX. Tradução: Jorge Enéas Fortes. Rio de Janeiro: Jorge Zahar Ed., 200I. (d)

TARDIF, Maurice. Saberes Docentes e Formação Profissional. Tradução: Francisco Pereira. II. ed. Petrópolis, RJ: Vozes, 2010. 